\title{
Is silence golden? Effects of auditory stimuli and their absence on adult hippocampal neurogenesis
}

\author{
Imke Kirste $\cdot$ Zeina Nicola $\cdot$ Golo Kronenberg • \\ Tara L. Walker · Robert C. Liu · Gerd Kempermann
}

Received: 9 July 2013/Accepted: 16 November 2013/Published online: 1 December 2013

(C) The Author(s) 2013. This article is published with open access at Springerlink.com

\begin{abstract}
We have previously hypothesized that the reason why physical activity increases precursor cell proliferation in adult neurogenesis is that movement serves as non-specific signal to evoke the alertness required to meet cognitive demands. Thereby a pool of immature neurons is generated that are potentially recruitable by subsequent cognitive stimuli. Along these lines, we here tested whether auditory stimuli might exert a similar non-specific effect on adult neurogenesis in mice. We used the standard noise level in the animal facility as baseline and compared this condition to white noise, pup calls, and silence. In addition, as patterned auditory stimulus without ethological relevance to mice we used piano music by Mozart (KV 448). All stimuli were transposed to the frequency range of C57BL/6 and hearing was objectified with acoustic evoked potentials. We found that except for white noise all stimuli,
\end{abstract}

I. Kirste · Z. Nicola · T. L. Walker · G. Kempermann ( $\square)$ CRTD, DFG Research Center for Regenerative Therapies Dresden, Fetscherstraße 105, 01307 Dresden, Germany e-mail: gerd.kempermann@crt-dresden.de; gerd.kempermann@dzne.de

\section{Kirste}

Brain Imaging and Analysis Center (BIAC), Duke University Medical Center, Durham, NC 27710, USA

G. Kronenberg

Klinik und Poliklinik für Psychiatrie und Psychotherapie, Charité- Universitätsmedizin Berlin, Charité Campus Mitte, 10117 Berlin, Germany

R. C. Liu

Department of Biology, Emory University, Atlanta, GA, USA

G. Kempermann

German Center for Neurodegenerative Diseases (DZNE)

Dresden, Arnoldstraße 18b, 01307 Dresden, Germany including silence, increased precursor cell proliferation (assessed $24 \mathrm{~h}$ after labeling with bromodeoxyuridine, BrdU). This could be explained by significant increases in BrdU-labeled Sox2-positive cells (type-1/2a). But after 7 days, only silence remained associated with increased numbers of BrdU-labeled cells. Compared to controls at this stage, exposure to silence had generated significantly increased numbers of BrdU/NeuN-labeled neurons. Our results indicate that the unnatural absence of auditory input as well as spectrotemporally rich albeit ethological irrelevant stimuli activate precursor cells-in the case of silence also leading to greater numbers of newborn immature neurons-whereas ambient and unstructured background auditory stimuli do not.

Keywords Plasticity $\cdot$ Stem cells $\cdot$ Hippocampus · Mouse $\cdot$ Learning

\section{Introduction}

Adult neurogenesis adds plasticity to the dentate gyrus of the hippocampus and is involved in key functions such as pattern separation (Aimone et al. 2010; Clelland et al. 2009) and avoidance of catastrophic interference (Appleby and Wiskott 2009; Wiskott et al. 2006) by adding flexibility to the network in situations where novel information has to be integrated into established representations (Garthe et al. 2009; Dupret et al. 2008). Adult neurogenesis is regulated by behavioral activity. Both physical activity and exposure to a challenging environment increase adult neurogenesis but do so by different means (Kronenberg et al. 2003). Non-specific stimuli like physical activity enhance the proliferation of precursor cells and lead to an increased potential in form of a larger pool of 
"neuroblasts" and immature neurons that can be recruited in case of a cognitive challenge. In contrast, exposure to an enriched environment promotes the survival of newborn neurons. Accordingly, the two interventions turned out to be additive in their effect (Fabel et al. 2009).

The new immature neurons own particular functionality in that they are more likely to generate action potentials in response to incoming stimuli due to their particular balance between excitatory and inhibitory input (Marin-Burgin et al. 2012). The threshold for LTP induction is reduced in these neurons (Schmidt-Hieber et al. 2004; Snyder et al. 2001). In fact, the LTP that is measurable in the dentate gyrus under physiological conditions is contributed by the newborn neurons during this critical period of their development (Garthe et al. 2009; Saxe et al. 2006). Thus, the immature new neurons are assumed to be more easily excitable than older cells, biasing the input towards the more plastic subpopulation of cells (Marin-Burgin et al. 2012). The hypothesis is that this mechanism allows flexible adaptation and learning of new information in previously established contexts. Non-specific stimuli would increase precursor cell proliferation to increase a pool of cells that can be recruited if cognitive demand arises (for detailed discussion see: Fabel et al. 2009).

The finding that exercise would have this effect on proliferation raised the question, whether other non-specific stimuli would also lead to an increased availability of potentially recruitable cells. Presumably, the intrinsic stimulus during physical activity essentially consists of proprioception and vision. Likewise, there are numerous reports on links between the vestibular system and hippocampal function [(Brandt et al. 2005); see Ref. Smith et al. (2010) for review] even though effects on adult neurogenesis have not yet been specifically addressed. In order to identify relevant sensory stimuli independent of locomotion, we here focused on auditory input as a potential signal to affect adult hippocampal neurogenesis.

Noise trauma with inner ear hair cell loss has led to a reduction of precursor cell proliferation in the hippocampus of rats (Kraus et al. 2010). A potential positive regulatory effect of sound on the early steps of adult hippocampal neurogenesis, however, has not yet been explored. We asked how different types of auditory stimuli would affect the baseline regulation of adult hippocampal neurogenesis (Fig. 1a).

We used ambient noise in the animal facility (animal house noise) as baseline and exposed our mice to four different conditions: (1) white noise as unstructured auditory stimulus; (2) mouse pup calls as structured stimulus that is for mice common and relevant; (3) Mozart piano music as a structured stimulus, unknown and presumably irrelevant to mice; and (4) silence.

\section{Materials and methods}

Animals

All experiments were performed according to national and institutional guidelines and were approved by the Institutional Animal Care and Use Committee (IACUC) of Emory University.

Forty female C57BL/6J mice were obtained from The Jackson Laboratory (Bar Harbor, Maine, USA) and were 6 to 8 weeks old at the beginning of the experiments. For all experiments, mice were held under standard laboratory housing conditions with a 12-h light/dark cycle and ad libitum access to food and water. Delivered mice were given a minimum of 5 days for habituation after arrival and housed in groups of five animals per cage $(N=10$ per group).

In comparison to other mouse strains, C57BL/6 animals have certain advantages in adult neurogenesis research because they typically show high neurogenic activity within the dentate gyrus, which responds readily to extrinsic stimuli (Kronenberg et al. 2003). We thus decided to use C57BL/6 despite the age-related presbyacusis that is typical for that strain (Hunter and Willott 1987).

\section{Auditory brainstem response}

To control for potential hearing loss, 10 additional animals were used for measurement of the auditory brainstem response $(\mathrm{ABR})$ in order to determine the average hearing ability of this strain at the given age of 8 weeks. This information was used to define the exposure parameters for the animals in the experiment.

Before testing, mice were anesthetized with $100 \mathrm{mg} / \mathrm{kg}$ body weight Ketamine and $0.3 \mathrm{mg} / \mathrm{kg}$ Medetomidine by intraperitoneal injection. During recording of the ABR, the eyes were covered with eye ointment to prevent dryness.

Once no more motor reflexes could be induced from the animal, silver wires were placed subdermally posterior to the stimulated ear, at the skull midline (ground) and at the contralateral bulla.

The recordings were done with a calibrated sound delivery system (Tucker-Davis Technologies, Gainesville, FL, USA) and BioSig program. Click trains and tones at 7, 32 or $65 \mathrm{kHz}$ were presented to the anesthetized females at a sampling rate of 223,214.06 per second. All tones were presented with $3 \mathrm{~ms}$ duration, intensity in the range of $0 \mathrm{~dB}$ SPL to $75 \mathrm{~dB}$ SPL, and an onset/offset ramp of $1.5 \mathrm{~ms}$. Auditory evoked activity was recorded, amplified $(\times 10,000)$, and filtered $(10 \mathrm{~Hz}-3 \mathrm{kHz})$. The hearing threshold was defined as the lowest intensity at which reliable responses were recorded. 


\section{A Timeline}

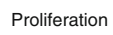

Differentiation
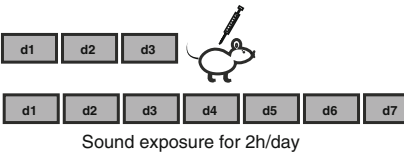

Sound exposure for $2 \mathrm{~h} / \mathrm{day}$

B Auditory brain stem response to clicks

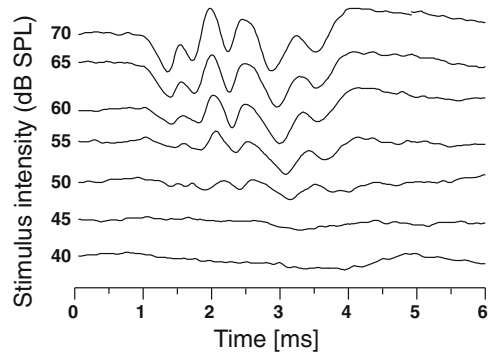

E Effects on proliferation: significance

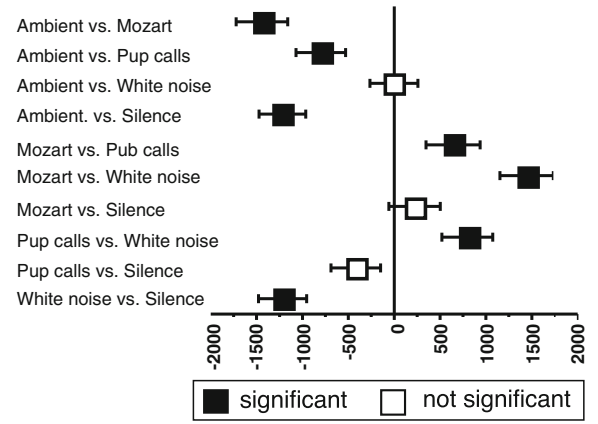

\section{Sound apparatus}

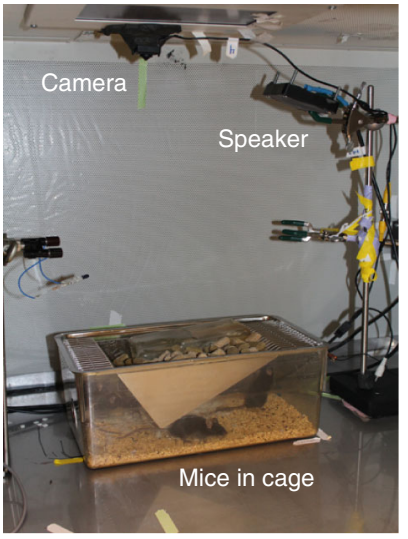

F BrdU+/Sox2+ cells
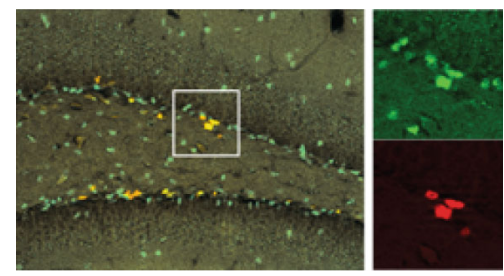

\section{Effects on proliferation}

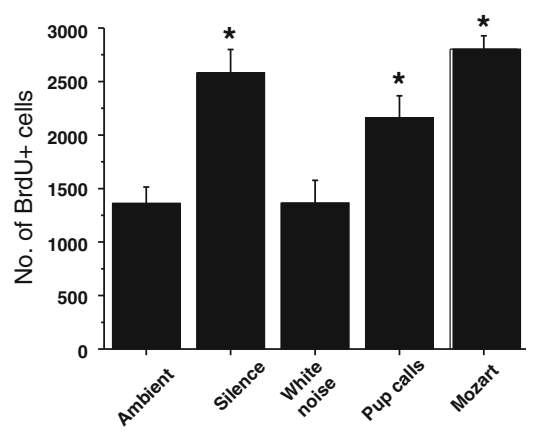

G Effects on BrdU+/Sox2+ cells

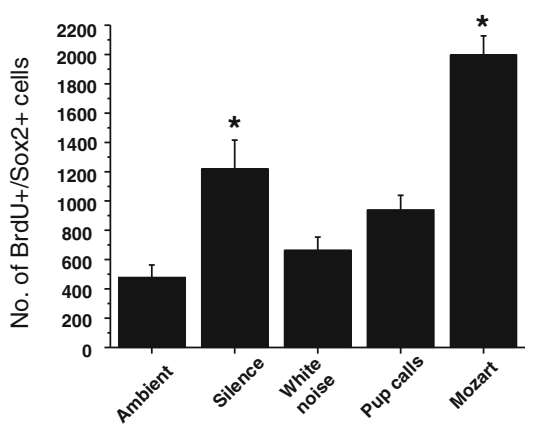

K Effects on differentiation

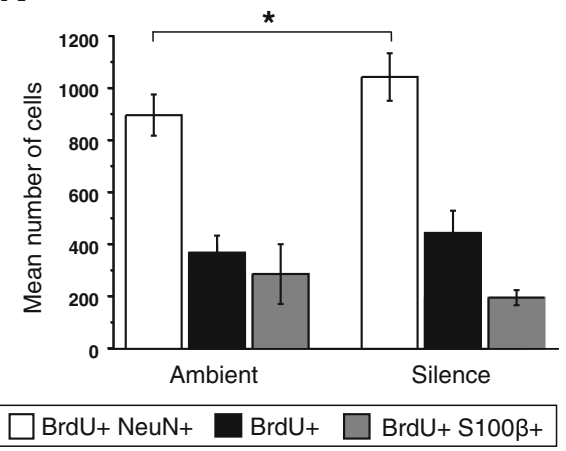

\section{H Effects on survival}

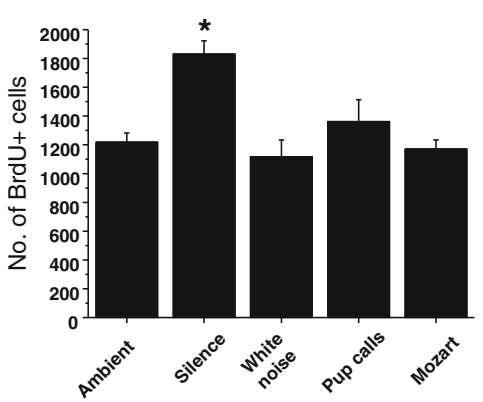

I Effects on survival: significance

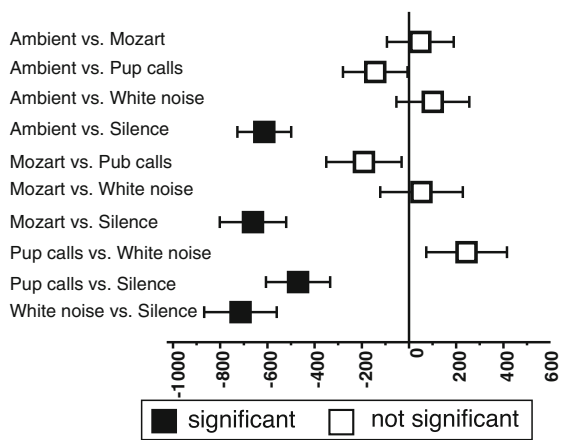

number of proliferating cells in the adult dentate gyrus, all other stimuli significantly increased the size of the population of BrdU+ cells $(\mathbf{d}, \mathbf{e}, \mathbf{a})$. In case of exposure to silence as well as Mozart's piano music (KV 448), we found particular increase in the population of BrdU-marked Sox2-positive precursor cells $(\mathbf{f}, \mathbf{g})$. The side length of the box in the large panel of (f) equals $150 \mu \mathrm{m}$. Differentiation, in contrast, was only significantly affected by silence $(\mathbf{h}, \mathbf{k})$ with a slight increase in the number of BrdU/NeuN double-positive new Neurons (i)

Exposure to sound stimuli

Ten animals of each group were placed into an anechoic sound isolation box (Acoustic Systems, Austin, TX, USA) for $2 \mathrm{~h} /$ day at the beginning of the dark phase of the lightobserved. 
dark cycle. Dependent on the experimental group, they were either exposed to standard animal house noise (group designated as "Ambient"), isolation from all sounds ("Silence"), white noise ("White noise", with a bandwidth of 4-80 kHz), previously recorded pup calls ("Pup calls") or Mozart's Sonata for two pianos in D major, KV 448 ("Mozart"). The music was presented with a sample rate of $97,656.25$ per second. The other sounds were presented at a sampling rate of 223,214.06 per second. The Mozart piece was transposed into the hearing range of $\mathrm{C} 57 \mathrm{BL} / 6 \mathrm{~J}$ mice. First, a low pass filter was set to $1,236 \mathrm{~Hz}$ and applied ten times to the music. The wav file was then transposed by five octaves. Afterwards a high-pass filter was set to $5,953 \mathrm{~Hz}$ and applied two times. Spectral analysis showed a peak at $10 \mathrm{kHz}$. More than $90 \%$ of the power lay between 5 and $20 \mathrm{kHz}$. Spectral analysis of the pup calls showed an average frequency of $65 \mathrm{kHz}$; the pup calls had been collected and modified as described elsewhere (Liu et al. 2003). The white noise was applied at an intensity of $70 \mathrm{~dB}$ SPL. All other stimuli varied in intensity $(70 \pm 10 \mathrm{~dB}$ SPL $)$.

\section{Immunohistochemistry}

To assess effects of auditory stimuli on precursor cell proliferation, the animals were exposed to the stimulus $2 \mathrm{~h} /$ day for 3 consecutive days, followed by an intraperitoneal injection of $50 \mathrm{mg} / \mathrm{kg}$ bodyweight Bromodeoxyuridine (BrdU, Sigma) $24 \mathrm{~h}$ after the last exposure (Fig. 1a). Again $24 \mathrm{~h}$ later, mice were killed and the brain was removed.

To address net neurogenesis (survival and differentiation), animals were injected with $\operatorname{BrdU}(50 \mathrm{mg} / \mathrm{kg})$ and exposed to auditory stimulus for seven consecutive days. Perfusion was performed $24 \mathrm{~h}$ after the last exposure. In this particular paradigm BrdU counts reflect early survival rates of newly generated cells.

For the collection of the brains, all animals were deeply anesthetized with a mixture of $10 \%$ Ketamine $(0.3 \mathrm{ml} /$ $20 \mathrm{~g}$ body weight $)$ and $2 \%$ Xylaxin $(0.1 \mathrm{ml} / 20 \mathrm{~g}$ bodyweight) and perfused transcardially with $0.9 \% \mathrm{NaCl}$ followed by $4 \%$ paraformaldehyde (PFA) in $0.1 \mathrm{M}$ KPBS buffer, $\mathrm{pH}$ 7.4. Brains were dissected from the skull, postfixed in $4 \%$ PFA at $4{ }^{\circ} \mathrm{C}$ for $24 \mathrm{~h}$ and then transferred into $30 \%$ sucrose in $0.1 \mathrm{M}$ phosphate buffer, $\mathrm{pH} 7.4$, for dehydration until they had sunk. Brains were then cut on a dry ice-cooled copper block with a table top sliding microtome (Leica, Bensheim) into $40-\mu \mathrm{m}$-thick coronal sections. Slides were stored at $4{ }^{\circ} \mathrm{C}$ in cryoprotectant solution containing $25 \%$ ethylene glycol, $25 \%$ glycerol, $25 \%$ glycerin and $0.05 \mathrm{M}$ phosphate buffer.

All sections were stained free floating with all antibodies diluted in Tris-buffered saline (TBS), $\mathrm{pH}$ 7.4, containing $3 \%$ donkey serum and $0.1 \%$ Triton X-100. For
BrdU-immunohistochemistry, one-in-six sections from each brain were transferred into TBS and washed briefly. Sections were pretreated with $0.6 \% \mathrm{H}_{2} \mathrm{O}_{2}$ to block endogenous tissue peroxidase. After rinsing in TBS, the DNA was denatured in $2 \mathrm{~N} \mathrm{HCl}$ for $30 \mathrm{~min}$ at $37^{\circ} \mathrm{C}$. Afterwards the sections were rinsed in $0.1 \mathrm{M}$ borate buffer, $\mathrm{pH} 8.5$, and thoroughly washed in TBS. Brain slices were incubated with the primary antibody overnight at $4{ }^{\circ} \mathrm{C}$. Primary and secondary antibodies were diluted in TBS supplemented with $0.1 \%$ Triton X-100 and $3 \%$ donkey serum (TBS-plus). As primary antibody we used rat anti-BrdU in a concentration of 1:500 (Harlan Seralab, Loughborough, UK). On the next day, the sections were rinsed in TBS and TBS-plus and incubated with the secondary antibody for $2 \mathrm{~h}$ at room temperature. As secondary antibody we used donkey anti-rat-biotin-SP (Dianova, Hamburg, Germany) at a concentration of 1:250. ABC reagent (Vectastain Elite, Vector Laboratories, Burlingame, CA, USA) was applied for $1 \mathrm{~h}$ at a concentration of $9 \mu \mathrm{l} / \mathrm{ml}$. Diaminobenzidine (DAB) (Sigma, Munich, Germany) was used as a chromogen at a concentration of $0.25 \mathrm{mg} / \mathrm{ml}$ in TBS with $0.01 \% \mathrm{H}_{2} \mathrm{O}_{2}$ and $0.04 \%$ nickel chloride. The stained sections were thoroughly washed, incubated in Neoclear for $10 \mathrm{~min}$ and mounted with Neomount.

\section{Immunofluorescence}

For immunofluorescence, 1-in-12 series of each brain were triple-labeled. The sections were transferred into TBS and washed briefly. The DNA was denatured in $2 \mathrm{~N} \mathrm{HCl}$ for $30 \mathrm{~min}$ at $37{ }^{\circ} \mathrm{C}$. Sections were then rinsed in $0.1 \mathrm{M}$ borate buffer, $\mathrm{pH} 8.5$, and thoroughly washed in TBS and TBSplus. The brain sections were incubated with the primary antibodies overnight at $4{ }^{\circ} \mathrm{C}$. Primary and secondary antibodies were diluted in TBS supplemented with $0.1 \%$ Triton X-100 and $3 \%$ donkey serum (TBS-plus). The next day, sections were rinsed in TBS and TBS-plus and incubated with secondary antibodies for $4 \mathrm{~h}$ at room temperature in the dark. Sections were then washed with TBS and coversliped in polyvinyl alcohol with diazabicyclooctane (DABCO) as anti-fading agent.

The primary antibodies were applied in the following concentrations: anti-BrdU (rat, 1:500; Harlan Seralab), anti-doublecortin (goat, 1:200; Santa Cruz Biotechnologies), anti-SOX2 (rabbit, 1:400, Chemicon, Temecula, USA), anti-NeuN (mouse, 1:100; Chemicon, Temecula, USA), anti-S100beta (rabbit, 1:2,500, Swant).

For secondary antibodies anti-rat rhodamine-X, antirabbit fluorescein isothiocyanate (FITC), anti-rabbit Cy5, anti-mouse FITC, anti-mouse Cy5, anti-goat Cy5 (all 1:250; Jackson Immunoresearch, West Grove, USA; distributor: Dianova, Hamburg, Germany) were used. 
Quantification and imaging

Quantification of cells labeled with DAB were determined using light microscopy on sections $240 \mu \mathrm{m}$ apart for BrdU covering the entire hippocampus in its rostrocaudal extension as described previously (Kronenberg et al. 2003). Briefly, cells located in the granule cell layer and adjacent subgranular zone, defined as a two-cell bodies-wide zone of the hilus along the base of the granule cell layer were counted. Cells in the uppermost focal plane were excluded to avoid oversampling. For light microscopical analyses, a Leica CTR 6000 Microscope was used.

Phenotypic analyses of BrdU-positive cells in the stated differentiation stages were performed using multiplestained series on sections $480 \mu \mathrm{m}$ apart, also covering the entire hippocampus, using a spectral confocal microscope (TCS SP2 and TCS SP5; Leica, Nussloch, Germany). Appropriate gain and black level settings were determined on control slices stained with secondary antibodies alone. All images were taken in sequential scanning mode and further processed in Adobe Photoshop 7.0 and CS3. Only general contrast adaptations were made and images were not otherwise manipulated.

\section{Statistical analysis}

Statistical analysis was performed either with Origin8 for Windows. Factorial analysis of variance (ANOVA) was performed for all comparisons of morphological data. Twoway ANOVA was followed by Fisher's post hoc test, where appropriate. Differences were considered statistically significant at $p<0.05$. All graphs are displayed as mean \pm standard error of the mean (SEM).

\section{Results}

With increasing age C57BL/6 mice undergo severe progressive sensorineural hearing loss (presbyacusis) starting around 4-5 months of age (Hunter and Willott 1987). To ensure the audibility of the auditory stimuli to our 2-monthold mice, we measured the auditory brainstem response (acoustic evoked potentials) to click sounds in C57BL/6 mice (Fig. 1b). This verified that the auditory stimuli that we intended to use in exposure would be above threshold for C57BL/6 at this age. Clicks equivalent to all of our stimuli are able to drive neural responses at the distinct frequency with the applied $70 \mathrm{~dB}$ SPL. Ambient baseline noise in the animal facility (Ambient) served as physiological baseline for our study.

Animals were exposed to the specific stimuli for $2 \mathrm{~h}$ per day for 3 days (Fig. 1a, c) in an anechoic chamber. One day after labeling cells with BrdU, White noise did not result in changing numbers of BrdU-positive cells, but all other stimuli increased proliferation (ANOVA: $F(4.39)=$ $12.17, p=1.62 \times 10^{-6}$, Fig. 1d, e). The greatest numbers of labeled cells were seen for Silence and Mozart. When we broke down these numbers according to the expression of Sox 2 as marker for early progenitor cell stages (type-1/ 2a, Fig. 1f), we saw that this increase was largely explained at this developmental stage (Fig. 1g). The stimuli indeed increased precursor cell proliferation.

At 7 days after division, the subset of cells that are destined for neuronal differentiation have exited from the cell cycle and only the minor fraction of label-retaining precursor cells remained proliferative (Encinas et al. 2011; Kempermann et al. 2003). The following period coincides with the electrophysiologically critical time window. We found that at this stage only the Silence group showed increased numbers of BrdU-positive cells, whereas all other groups were indistinguishable from the Ambient controls (ANOVA: $F(4.42)=10.73, p=1.41251 \times 10^{-6}$ Fig. 1h, i). The Silence and Ambient groups were further analyzed for the phenotype of the newborn cells. As known from other experiments, approximately two-thirds of these cells were neurons (based on NeuN expression) and around $15 \%$ were S100 $\beta$-positive astrocytes. The proportion of neurons was increased to $62 \%$ in the silence condition from $57 \%$ in the Ambient noise group and the difference barely missed conventional statistical significance $(p=0.056)$. In absolute terms, Silence resulted in statistically increased levels of neurogenesis (BrdU/NeuN-double-positive cells) at this stage ( $p=0.008$, Fig. 1k).

\section{Discussion}

The present study shows that auditory stimuli can induce a response at the level of adult neurogenesis compared to normal baseline ambient noise or unstructured white noise. More interestingly, however, we found that silence and ethologically irrelevant sounds (Mozart) showed a stronger on proliferation effect than presumably natural and relevant sounds like pup calls. Both Mozart and Silence also represent highly novel stimuli, in line with the idea that adult hippocampal neurogenesis plays a role in the integration of novel information into pre-existing contexts.

To our initial surprise, silence, i.e., the complete absence of auditory input, was the only stimulus that elicited a strong response at the level of immature ( 7 day old) new neurons. But of the tested paradigms, silence might be the most arousing, because it is highly atypical under wild conditions and must thus be perceived as alerting. Functional imaging studies indicate that trying to hear in silence activates the auditory cortex, putting "the sound of 
silence", the absence of expected sound, at the same level with actual sounds (Kraemer et al. 2005; Voisin et al. 2006). The alert elicited by such unnatural silence might stimulate neurogenesis as preparation for future cognitive challenges.

As in our previous set of experiments, one could now call for a combination of the non-specific and the specific stimulus in order to see whether a learning stimulus can recruit new neurons from the pool of new neurons generated in response to exposure to silence, as was the case for physical activity (Fabel et al. 2009). Given the small effect size here and challenges to the experimental design because of the different temporal properties of the two stimuli, this experiment is not trivial and, if done, should possibly be included into larger-scale studies on the general mechanisms underlying such two-step regulation. Based on the available data, we would predict that silence-activated progenitor cells should be usable for the response to cognitive challenges, because these new neurons have survived the initial wave of cell death after cell birth in the adult hippocampus (Kempermann et al. 2003) and are in a time window or critical period, during which the survival-promoting forces are effective (Tashiro et al. 2007; Kee et al. 2007; Gould et al. 1999).

Loud white noise can be a strong stressor (Lai 1987; Cheng et al. 2011). In our study, we purposefully used white noise that did not reach this damaging level. Our data did not reveal any substantial difference between ambient animal house noise and white noise. The white noise condition thus also serves as control for the anechoic chamber in which the animals were exposed to the sounds.

In any case, the role of stress in the regulation of adult hippocampal neurogenesis is complex. While strong acute social stress downregulates adult neurogenesis, the picture is less clear in other situations (Lucassen et al. 2010). The experience of sudden silence will represent a stressor, but so does the exposure to a running wheel (Van Praag et al. 1999). So the presence of stress per se is not incompatible with an increase in adult neurogenesis and the activation that is required for the neurogenic response might even be considered as "good stress" or eustress.

While few humans will agree that Mozart is "ethologically irrelevant noise," for mice it should be. We have chosen Mozart's Sonata for two pianos (KV 448) somewhat tongue-in-cheek, because it has received a notorious reputation in the context of the so-called "Mozart effect", the controversial claim that listening to this sonata was sufficient to elicit improved learning in humans (Fudin and Lembessis 2004; Jenkins 2001). One study claimed that the effect on humans could be replicated in rats (Rauscher et al. 1998) and one report showed improved T-maze learning in mice after exposure to Mozart but not Beethoven (Aoun et al. 2005). The "Mozart effect" is largely discredited, also due to a rather unprecedented financial exploitation, even though there are actually interesting observations related to this paradigm, including reproducible studies on reduced epileptiform changes in the EEG (Lin et al. 2011) or on energy expenditure in preterm infants (Lubetzky et al. 2010). Such results are usually explained through an arousal elicited by the music (Lubetzky et al. 2010; Steele 2000). In this view, the Mozart piece KV 448 (first movement) would be nothing more but a particularly effective way to elicit a quite generic response. What is characteristic about the particular piece, however, is that it is highly patterned and has a rather fast beat. It represents an auditory stimulus that is not natural to mice and does not convey ethologically relevant information about the world. Nevertheless, its patterned nature might still resonate with sensory and cognitive mechanisms available to the mouse (compare, for example: (Schneider et al. 2010)). It would represent a stimulus of novelty and might thus also affect neurogenesis. We found that exposure to Mozart indeed induced an arousal-like effect at the precursor cell level. Unlike the complete absence of auditory signals, however, this increase in proliferating Sox2positive cells was not followed by an increased availability of immature neurons. Why that might be, we can only speculate, but the important conclusion here is that regulation of neurogenesis obviously responds differentially to different auditory stimuli.

Adult neurogenesis has been hypothesized as crucial for flexible adaptations to environmental changes and thus displays an evolutionary advantage (Kempermann 2012). Modulation of the dentate gyrus cytoarchitecture caused by auditory stimuli is a particular case of experiencing the outside world, to which the animal has to respond. Our findings of different neurogenic responses to sounds be they structured or unstructured, relevant or irrelevant, and even present or absent, might reflect the preparation for novel information and behavioral contingencies, and thus increase the ability to adapt to environmental changes. Indeed, as acoustic stimuli (or possibly their absence) gain meaning to an animal through experience, auditory cortical plasticity occurs that may functionally improve the processing of those sounds, as has been demonstrated for pup calls (Liu and Schreiner 2007; Galindo-Leon et al. 2009).

Studies on auditory-dependent learning have also revealed changes in hippocampal activation (McIntosh and GonzalezLima 1998; Grasby et al. 1993), and the conscious perception of sounds appears to activate the hippocampus (Laureys et al. 2000). These therefore support the idea that the hippocampus is also a site of higher order integration of sensory inputs (Braak et al. 1996; Jones and Powell 1970).

Acknowledgements This study was financed from basic institutional funds, with support from NIH DC008343. During her work on 
this project IK was a fellow of Max Planck International Research School LIFE, Berlin. We are grateful to Dr. Anje Sporbert at Max Delbrück Center for Molecular Medicine (MDC) Berlin-Buch to support this project by providing technical assistance and access to the Confocal Microscope, and Dr. Annette Hammes for access to the Leica CTR 6000.

Conflict of interest The authors declare no competing financial interests.

Open Access This article is distributed under the terms of the Creative Commons Attribution License which permits any use, distribution, and reproduction in any medium, provided the original author(s) and the source are credited.

\section{References}

Aimone JB, Deng W, Gage FH (2010) Adult neurogenesis: integrating theories and separating functions. Trends Cogn Sci 14(7):325-337 (pii: S1364-6613(10)00088-4)

Aoun P, Jones T, Shaw GL, Bodner M (2005) Long-term enhancement of maze learning in mice via a generalized Mozart effect. Neurol Res 27(8):791-796. doi:10.1179/016164105X63647

Appleby PA, Wiskott L (2009) Additive neurogenesis as a strategy for avoiding interference in a sparsely-coding dentate gyrus. Network 20(3):137-161 (pii: 914288016)

Braak H, Braak E, Yilmazer D, Bohl J (1996) Functional anatomy of human hippocampal formation and related structures. J Child Neurol 11(4):265-275

Brandt T, Schautzer F, Hamilton DA, Bruning R, Markowitsch HJ, Kalla R, Darlington C, Smith P, Strupp M (2005) Vestibular loss causes hippocampal atrophy and impaired spatial memory in humans. Brain 128(Pt 11):2732-2741. doi:10.1093/brain/ awh617

Cheng L, Wang SH, Chen QC, Liao XM (2011) Moderate noise induced cognition impairment of mice and its underlying mechanisms. Physiol Behav 104(5):981-988. doi:10.1016/j. physbeh.2011.06.018

Clelland CD, Choi M, Romberg C, Clemenson GD Jr, Fragniere A, Tyers P, Jessberger S, Saksida LM, Barker RA, Gage FH, Bussey TJ (2009) A functional role for adult hippocampal neurogenesis in spatial pattern separation. Science 325(5937): 210-213

Dupret D, Revest JM, Koehl M, Ichas F, De Giorgi F, Costet P, Abrous DN, Piazza PV (2008) Spatial relational memory requires hippocampal adult neurogenesis. PLoS ONE 3(4):e1959

Encinas JM, Michurina TV, Peunova N, Park JH, Tordo J, Peterson DA, Fishell G, Koulakov A, Enikolopov G (2011) Divisioncoupled astrocytic differentiation and age-related depletion of neural stem cells in the adult hippocampus. Cell Stem Cell 8(5):566-579 (pii: S1934-5909(11)00120-2)

Fabel K, Wolf SA, Ehninger D, Babu H, Galicia PL, Kempermann G (2009) Additive effects of physical exercise and environmental enrichment on adult hippocampal neurogenesis in mice. Front Neurosci 3:50. doi:10.3389/neuro.22.002.2009

Fudin R, Lembessis E (2004) The Mozart effect: questions about the seminal findings of Rauscher, Shaw, and colleagues. Percept Mot Skills 98(2):389-405

Galindo-Leon EE, Lin FG, Liu RC (2009) Inhibitory plasticity in a lateral band improves cortical detection of natural vocalizations. Neuron 62(5):705-716. doi:10.1016/j.neuron.2009.05.001

Garthe A, Behr J, Kempermann G (2009) Adult-generated hippocampal neurons allow the flexible use of spatially precise learning strategies. PLoS ONE 4(5):e5464
Gould E, Beylin A, Tanapat P, Reeves A, Shors TJ (1999) Learning enhances adult neurogenesis in the hippocampal formation. Nat Neurosci 2(3):260-265

Grasby PM, Frith CD, Friston K, Frackowiak RS, Dolan RJ (1993) Activation of the human hippocampal formation during auditoryverbal long-term memory function. Neurosci Lett 163(2): $185-188$

Hunter KP, Willott JF (1987) Aging and the auditory brainstem response in mice with severe or minimal presbycusis. Hear Res 30(2-3):207-218

Jenkins JS (2001) The Mozart effect. J R Soc Med 94(4):170-172

Jones EG, Powell TP (1970) An anatomical study of converging sensory pathways within the cerebral cortex of the monkey. Brain 93(4):793-820

Kee N, Teixeira CM, Wang AH, Frankland PW (2007) Preferential incorporation of adult-generated granule cells into spatial memory networks in the dentate gyrus. Nat Neurosci 10(3): $355-362$

Kempermann G (2012) New neurons for 'survival of the fittest'. Nat Rev Neurosci 13(10):727-736. doi:10.1038/nrn3319

Kempermann G, Gast D, Kronenberg G, Yamaguchi M, Gage FH (2003) Early determination and long-term persistence of adultgenerated new neurons in the hippocampus of mice. Development 130(2):391-399

Kraemer DJ, Macrae CN, Green AE, Kelley WM (2005) Musical imagery: sound of silence activates auditory cortex. Nature 434(7030):158. doi:10.1038/434158a

Kraus KS, Mitra S, Jimenez Z, Hinduja S, Ding D, Jiang H, Gray L, Lobarinas E, Sun W, Salvi RJ (2010) Noise trauma impairs neurogenesis in the rat hippocampus. Neuroscience 167(4): 1216-1226. doi:10.1016/j.neuroscience.2010.02.071

Kronenberg G, Reuter K, Steiner B, Brandt MD, Jessberger S, Yamaguchi M, Kempermann G (2003) Subpopulations of proliferating cells of the adult hippocampus respond differently to physiologic neurogenic stimuli. J Comp Neurol 467(4):455463

Lai H (1987) Acute exposure to noise affects sodium-dependent highaffinity choline uptake in the central nervous system of the rat. Pharmacol Biochem Behav 28(2):147-151

Laureys S, Faymonville ME, Degueldre C, Fiore GD, Damas P, Lambermont B, Janssens N, Aerts J, Franck G, Luxen A, Moonen G, Lamy M, Maquet P (2000) Auditory processing in the vegetative state. Brain 123(Pt 8):1589-1601

Lin LC, Lee WT, Wang CH, Chen HL, Wu HC, Tsai CL, Wei RC, Mok HK, Weng CF, Lee MW, Yang RC (2011) Mozart K.448 acts as a potential add-on therapy in children with refractory epilepsy. Epilepsy Behav 20(3):490-493. doi:10.1016/j.yebeh.2010.12.044

Liu RC, Schreiner CE (2007) Auditory cortical detection and discrimination correlates with communicative significance. PLoS Biol 5(7):e173. doi:10.1371/journal.pbio.0050173

Liu RC, Miller KD, Merzenich MM, Schreiner CE (2003) Acoustic variability and distinguishability among mouse ultrasound vocalizations. J Acoust Soc Am 114(6 Pt 1):3412-3422

Lubetzky R, Mimouni FB, Dollberg S, Reifen R, Ashbel G, Mandel D (2010) Effect of music by Mozart on energy expenditure in growing preterm infants. Pediatrics 125(1):e24-e28. doi:10. 1542/peds.2009-0990

Lucassen PJ, Meerlo P, Naylor AS, van Dam AM, Dayer AG, Fuchs E, Oomen CA, Czeh B (2010) Regulation of adult neurogenesis by stress, sleep disruption, exercise and inflammation: implications for depression and antidepressant action. Eur Neuropsychopharmacol 20(1):1-17. doi:10.1016/j.euroneuro.2009.08.003

Marin-Burgin A, Mongiat LA, Pardi MB, Schinder AF (2012) Unique processing during a period of high excitation/inhibition balance in adult-born neurons. Science 335(6073):1238-1242. doi:10. 1126/science. 1214956 
McIntosh AR, Gonzalez-Lima F (1998) Large-scale functional connectivity in associative learning: interrelations of the rat auditory, visual, and limbic systems. J Neurophysiol 80(6): 3148-3162

Rauscher FH, Robinson KD, Jens JJ (1998) Improved maze learning through early music exposure in rats. Neurol Res 20(5):427-432

Saxe MD, Battaglia F, Wang JW, Malleret G, David DJ, Monckton JE, Garcia AD, Sofroniew MV, Kandel ER, Santarelli L, Hen R, Drew MR (2006) Ablation of hippocampal neurogenesis impairs contextual fear conditioning and synaptic plasticity in the dentate gyrus. Proc Natl Acad Sci USA 103(46):17501-17506

Schmidt-Hieber C, Jonas P, Bischofberger J (2004) Enhanced synaptic plasticity in newly generated granule cells of the adult hippocampus. Nature 429(6988):184-187

Schneider S, Askew CD, Abel T, Struder HK (2010) Exercise, music, and the brain: is there a central pattern generator? J Sports Sci 28(12):1337-1343. doi:10.1080/02640414.2010.507252

Smith PF, Darlington CL, Zheng Y (2010) Move it or lose it-is stimulation of the vestibular system necessary for normal spatial memory? Hippocampus 20(1):36-43. doi:10.1002/hipo.20588
Snyder JS, Kee N, Wojtowicz JM (2001) Effects of adult neurogenesis on synaptic plasticity in the rat dentate gyrus. J Neurophysiol 85(6):2423-2431

Steele KM (2000) Arousal and mood factors in the "Mozart effect". Percept Mot Skills 91(1):188-190

Tashiro A, Makino H, Gage FH (2007) Experience-specific functional modification of the dentate gyrus through adult neurogenesis: a critical period during an immature stage. J Neurosci 27(12): 3252-3259

Van Praag H, Kempermann G, Gage FH (1999) Running increases cell proliferation and neurogenesis in the adult mouse dentate gyrus. Nat Neurosci 2(3):266-270

Voisin J, Bidet-Caulet A, Bertrand O, Fonlupt P (2006) Listening in silence activates auditory areas: a functional magnetic resonance imaging study. J Neurosci 26(1):273-278. doi:10.1523/ JNEUROSCI.2967-05.2006

Wiskott L, Rasch MJ, Kempermann G (2006) A functional hypothesis for adult hippocampal neurogenesis: avoidance of catastrophic interference in the dentate gyrus. Hippocampus 16(3):329-343. doi: 10.1371/journal.pcbi.1001063 